\title{
The Judicious Use of Stereotactic Radiosurgery and Hypofractionated Stereotactic Radiotherapy in the Management of Large Brain Metastases
}

\author{
Tyler Gutschenritter ${ }^{1}$, Vyshak A. Venur ${ }^{2}$, Stephanie E. Combs ${ }^{3,4}{ }^{,}$Balamurugan Vellayappan ${ }^{5}$, Anoop P. Patel ${ }^{6}$, \\ Matthew Foote ${ }^{7}$, Kristin J. Redmond ${ }^{8}$, Tony J. C. Wang ${ }^{9}{ }^{(1)}$, Arjun Sahgal ${ }^{10}$, Samuel T. Chao ${ }^{11}$, John H. Suh ${ }^{11}$,
} Eric L. Chang ${ }^{12}$, Richard G. Ellenbogen ${ }^{6}$ and Simon S. Lo ${ }^{1, *}$

check for

updates

Citation: Gutschenritter, T.; Venur, V.A.; Combs, S.E.; Vellayappan, B.; Patel, A.P.; Foote, M.; Redmond, K.J.; Wang, T.J.C.; Sahgal, A.; Chao, S.T.; et al. The Judicious Use of Stereotactic Radiosurgery and Hypofractionated Stereotactic Radiotherapy in the Management of Large Brain Metastases. Cancers 2021, 13, 70. https://doi.org/10.3390/cancers 13010070

Received: 16 November 2020 Accepted: 18 December 2020 Published: 29 December 2020

Publisher's Note: MDPI stays neutral with regard to jurisdictional clai$\mathrm{ms}$ in published maps and institutional affiliations.

Copyright: (C) 2020 by the authors. Licensee MDPI, Basel, Switzerland. This article is an open access article distributed under the terms and conditions of the Creative Commons Attribution (CC BY) license (https:// creativecommons.org/licenses/by/ $4.0 /)$.
1 Department of Radiation Oncology, University of Washington School of Medicine, Seattle, WA 98195, USA; tylergut@uw.edu

2 Division of Medical Oncology, University of Washington School of Medicine, Seattle, WA 98195, USA; vyshakav@uw.edu

3 Department of Radiation Oncology, Klinikum rechts der Isar, Technical University of Munich (TUM), 81675 Munich, Germany; Stephanie.combs@tum.de

4 Institute for Radiation Medicine (IRM), Helmholtz Zentrum München, 85764 Neuherberg, Germany

5 Department of Radiation Oncology, National University Cancer Institute, Singapore 119074, Singapore; Bala_vellayappan@nuhs.edu.sg

6 Department of Neurological Surgery, University of Washington School of Medicine, Seattle, WA 98195, USA; apatel1@uw.edu (A.P.P.); rge@neurosurgery.washington.edu (R.G.E.)

7 Department of Radiation Oncology, Princess Alexandra Hospital, University of Queensland, ICON Cancer Care, Brisbane 4072, Australia; matthew.foote@health.qld.gov.au

8 Department of Radiation Oncology and Molecular Radiation Sciences, The Johns Hopkins University, Baltimore, MD 21093, USA; kjanson3@jhmi.edu

9 Department of Radiation Oncology, Columbia University Irving Medical Center, New York, NY 10032, USA tjw2117@cumc.columbia.edu

10 Department of Radiation Oncology, Odette Cancer Centre, Toronto, ON M4N 3M5, Canada; arjun.sahgal@sunnybrook.ca

11 Department of Radiation Oncology, Cleveland Clinic, Cleveland, OH 44195, USA; chaos@ccf.org (S.T.C.); suhj@ccf.org (J.H.S.)

12 Department of Radiation Oncology, University of Southern California Keck School of Medicine, Los Angeles, CA 90033, USA; eric.chang@med.usc.edu

* Correspondence: simonslo@uw.edu; Tel.: +1-206-598-4100

Simple Summary: Brain metastases are the most common cause of cancerous brain tumors in adults. Large brain metastases are an especially difficult clinical scenario as patients often have debilitating symptoms from these tumors, and large tumors are more difficult to control with traditional single treatment radiation regimens alone or after surgery. Hypofractionated stereotactic radiotherapy is a novel way to deliver the higher doses of radiation to control large tumors either after surgery (most common), alone (common), or potentially before surgery (uncommon). Herein, we describe how delivering high doses over three or five treatments may improve tumor control and decrease complication rates compared to more traditional single treatment regimens for brain metastases larger than $2 \mathrm{~cm}$ in maximum dimension.

Abstract: Brain metastases are the most common intracranial malignant tumor in adults and are a cause of significant morbidity and mortality for cancer patients. Large brain metastases, defined as tumors with a maximum dimension $>2 \mathrm{~cm}$, present a unique clinical challenge for the delivery of stereotactic radiosurgery (SRS) as patients often present with neurologic symptoms that require expeditious treatment that must also be balanced against the potential consequences of surgery and radiation therapy - namely, leptomeningeal disease (LMD) and radionecrosis (RN). Hypofractionated stereotactic radiotherapy (HSRT) and pre-operative SRS have emerged as novel treatment techniques to help improve local control rates and reduce rates of RN and LMD for this patient population commonly managed with post-operative SRS. Recent literature suggests that pre-operative SRS can potentially half the risk of LMD compared to post-operative SRS and that HSRT can improve 
risk of RN to less than $10 \%$ while improving local control when meeting the appropriate goals for biologically effective dose (BED) and dose-volume constraints. We recommend a 3- or 5-fraction regimen in lieu of SRS delivering $15 \mathrm{~Gy}$ or less for large metastases or resection cavities. We provide a table comparing the BED of commonly used SRS and HSRT regimens, and provide an algorithm to help guide the management of these challenging clinical scenarios.

Keywords: stereotactic radiosurgery; hypofractionated stereotactic radiotherapy; large brain metastases; radionecrosis; local control

\section{Introduction}

Brain metastases are the most common intracranial malignant tumor in adults and are a cause of significant morbidity and mortality for cancer patients [1,2]. The incidence of brain metastases in adults with solid tumors ranges between $10-30 \%$ and is dependent on histology and stage [3-5]. The histologies that account for the majority of brain metastases cases are non-small cell lung cancer (NSCLC), breast cancer, and melanoma [4]. Of patients with metastatic cancer at the time of initial diagnosis, an estimated $12 \%$ have brain metastases at diagnosis [1].

Patients with metastatic cancer, including those with brain metastases, are living longer due to recent improvements in systemic agents and radiation therapy [6-8]. However, the variability of central nervous system (CNS) penetration of novel systemic agents necessitates continued improvement of radiation therapy techniques for brain metastases. Current guidelines recommend definitive stereotactic radiosurgery (SRS) alone or in conjunction with surgical resection for patients with a limited number of brain metastases and good performance status $[9,10]$. SRS has largely supplanted definitive or post-operative whole brain radiation therapy (WBRT) for these patients after multiple studies demonstrated a decline in quality of life and neurocognitive function without providing a survival benefit [11-16].

Large brain metastases present a unique and common clinical challenge for the delivery of SRS. The published definition of "large" varies from $>2 \mathrm{~cm}$ up to $\geq 4 \mathrm{~cm}$ in maximum diameter [17-23]. Patients often present with neurologic symptoms from vasogenic edema and mass effect, which makes definitive SRS a suboptimal treatment choice given the lack of immediate relief and risk of transient neurologic deterioration following treatment. Moreover, even post-operative SRS to a large resection cavity carries an increased risk of radionecrosis $(\mathrm{RN})$ and may require dose reduction, potentially compromising local control $[19,24-32]$.

Herein, we will review the recent developments in novel radiation and surgical treatment paradigms for managing large brain metastases and provide strategies for delivering SRS or hypofractionated stereotactic radiation therapy (HSRT) for a variety of clinical scenarios. For the purpose of this paper, we will define large brain metastases as $>2 \mathrm{~cm}$ in maximal diameter but recognize that this definition is controversial and not universally accepted.

\section{Optimal Approach for Utilizing Surgery and SRS}

Post-operative radiation therapy prolongs overall survival in patients with a single brain metastasis and improves local control in patients with multiple brain metastases $[11,15,33,34]$. The 1-year local control rate following surgery without post-operative treatment is estimated to be $40-50 \%[15,33,34]$. The 1-year local control rate with the addition of post-operative SRS is estimated to be $70-80 \%$ [11,15]. However, the 1-year local control rate for tumors $>2 \mathrm{~cm}$ treated definitively or post-operatively with SRS leaves much room for improvement, with estimates ranging between $40 \%$ and $50 \%[15,19,30-32]$. 


\subsection{The Added Benefit of Resection to SRS}

While post-operative radiation therapy has become the standard of care following resection of a brain metastasis, there is limited data comparing definitive SRS alone vs. surgical resection followed by SRS in patients with a limited number of brain metastases. Quigley et al. retrospectively examined local control and overall survival in 163 patients with 4 brain metastases or less who underwent either SRS alone $(n=113)$ or resection followed by post-operative SRS $(n=49)$ [35].

The resection plus SRS group had larger maximal tumor dimension $(2.8 \mathrm{~cm}$ vs. $1.5 \mathrm{~cm})$ and target volumes $(9.9 \mathrm{~mL}$ vs. $3.6 \mathrm{~mL})$, which resulted in lower average prescription dose (15.8 Gy vs. 17.5 Gy) compared to SRS alone. Gross total resection (GTR) was the only prognostic factor that significantly improved both local control and overall survival $(p=0.015$ and $p=0.010)$. Furthermore, increased tumor volume was associated with significantly worse local control $(p=0.02)$, which is presumably related to the lower prescription doses delivered to these tumors or resection cavities. Overall, the results suggest that GTR plus post-operative SRS can provide excellent local control ( 22.5 months compared to 14.8 months for SRS alone) for patients with tumors $>2 \mathrm{~cm}$ and can improve survival outcomes in select patients.

Prabhu et al. published a larger multi-institutional retrospective analysis examining local control and overall survival in 213 patients with 223 large brain metastases $(>2 \mathrm{~cm}$ diameter) who either received SRS alone or GTR plus SRS [36]. There were 66 brain metastases in the SRS alone group and 157 brain metastases in the GTR plus SRS group. In contrast to Quigley et al., this study required GTR for inclusion, allowed for pre-operative SRS, and utilized competing risk analysis, which reduces overestimating rates of local recurrence when death is a competing risk.

Overall survival and local control were significantly improved in the GTR plus SRS arm. The SRS alone group had a median overall survival of 10 months compared to 15.2 months with GTR plus SRS $(p=0.01)$. The local failure rates at both 1 year and 2 years were significantly lower in the GTR plus SRS arm (1-year: $20.5 \%$ vs. $36.7 \%$; 2 -year: $25.6 \%$ vs. $43.1 \% ; p=0.007)$. There was no significant difference in overall survival, local control, and LMD when comparing pre-operative and post-operative SRS. However, the post-operative SRS group had significantly higher 1-year and 2-year rates of RN when compared to preoperative SRS and SRS alone (1-year: $22.6 \%$ vs. $12.3 \%$ and $5 \%$; 2 -year: $33.5 \%$ vs. $17.2 \%$ and $9 \% ; p<0.001)$.

Taken together, the above studies both demonstrate that GTR plus SRS improves local control and overall survival in patients with brain metastases $>2 \mathrm{~cm}$, a limited number of brain metastases, and good performance status (ECOG 0-2). The average maximum tumor diameter for SRS alone groups was $1.5 \mathrm{~cm}$ in the Quigley et al. study and $2.25 \mathrm{~cm}$ in the Prabhu et al. study, but the tumor volumes in the resection plus SRS groups were similar $(8.7 \mathrm{~mL}$ and $9.6 \mathrm{~mL}$ ) between studies. Both delivered similar dose regimens for SRS alone (median dose: 17.5 and 18 Gy) and for resection plus SRS (15.8 and 15 Gy).

\subsection{Pre-Operative versus Post-Operative SRS for Large Brain Metastases}

Recently, much attention has been given to the optimal timing of SRS in the context of planned resection. This is a critical consideration in the treatment for large brain metastases that often present with neurologic symptoms, impending neurologic compromise, and/or significant vasogenic edema or mass effect—all of which are best managed with upfront surgical resection if possible. Post-operative SRS is currently considered the standard approach for all brain metastases, irrespective of size, when resection is required [11,15]. However, there are drawbacks to post-operative SRS, such as the following: (1) postoperative complications delaying initiation of radiation, especially with the more extensive resections required for large brain metastases; (2) the need for 1-mm or 2-mm expansion to the operative bed for optimal local control; and (3) the variable resection cavity dynamics between immediate post-operative MRI and SRS treatment planning MRI [37-39]. We have 
provided an overview of the advantages and disadvantages for SRS alone, post-operative SRS, and pre-operative SRS in Table 1 that we will discuss further in the following sections.

Table 1. Overview of the comparative advantages and disadvantages of SRS alone, post-operative SRS, and pre-operative SRS.

\begin{tabular}{cccc}
\hline Parameter & SRS Alone & Post-Op SRS & Pre-Op SRS \\
\hline Delay of systemic therapy & Minimal & Significant & Significant \\
Relief of neurologic symptoms & Risk of worsening & Immediate & Risk of worsening \\
CTV Margin & None & $1-3 \mathrm{~mm}$ & None \\
Overall Survival & Worse & Better & Better \\
Local Control & Worse & Better & Better \\
1-year LMD Risk & $5-7 \%[40-42]$ & $7-30 \%[11,15,43,44]$ & $\leq 5 \%[45,46]$ \\
1-year RN Risk & $5-20 \%[36,47,48]$ & $3-25 \%[11,36,38,39]$ & $5-10 \%[36,45,49]$ \\
Prescribed Dose & Per RTOG 9005 & Per N107C or A071801 & $20 \%$ Reduced \\
Timing & Within days & $2-6$ weeks post-op & 48 hre-op \\
\hline
\end{tabular}

\subsubsection{Challenges of Post-Operative SRS for Large Brain Metastases}

In regards to the data by Choi et al., this study retrospectively evaluated 120 cavities in 112 patients who received post-operative SRS and did not have prior intracranial radiation therapy. These results demonstrated significantly decreased 1-year local failure rates (3\% vs. $16 \% ; p=0.042$ ) without increased toxicity when placing uniform 2-mm expansion on the resection cavity compared to no expansion, but there was an increase in median planning target volume (PTV) by 55\% with the 2-mm expansion [39]. However, likely due to the concern for an increased risk of $\mathrm{RN}$ with larger resection cavities, a 2-mm expansion has not been uniformly adopted for post-operative SRS. Specifically, a single institution, randomized controlled trial by Mahajan et al. examining post-operative SRS versus observation following surgical resection utilized only a 1-mm uniform expansion for PTV creation [15]. In contrast, a multi-institutional randomized controlled trial (N107C) examining post-operative SRS vs. post-operative whole brain radiation therapy (WBRT) utilized a uniform 2-mm expansion for PTV creation [11].

A recent retrospective analysis by Jhaveri et al. compared 1-mm expansion vs. >1-mm expansion (median $1.9 \mathrm{~mm}$, mean $2.0 \mathrm{~mm}$ ) for resected brain metastases in 133 patients with 139 cavities (1-mm group: 36 patients with 35 cavities; >1-mm group: 97 patients with 104 cavities) [38]. This study demonstrated that a 1-mm expansion had a similar 1-year local recurrence rate $(15.2 \%$ vs. $14.3 \%)$ with a significantly lower risk of symptomatic RN compared to $>1 \mathrm{~mm}$ expansion (1-year: $6 \%$ vs. $20.9 \%$; 2 -year: $9.1 \%$ vs. $26.6 \%$; $p=0.028$ ). Of note, HSRT was also associated with a significantly reduced risk of symptomatic RN (HR $0.13 ; p=0.023)$.

The only factor associated with increased risk of local recurrence on multivariate analysis was a resection cavity volume $>15 \mathrm{~mL}(\mathrm{HR} 4.23 ; p=0.047)$, which is an estimated 3.06-cm max dimension using spherical modeling. This study had a larger median resection cavity volume compared to the Choi et al. data $(11.3 \mathrm{~mL}$ vs. $8.5 \mathrm{~mL})$ and had slightly higher rates of local recurrence compared to Choi et al. (14-15\% vs. 9\%), likely due to the larger average cavity size. Overall, this study along with the data from Mahajan et al. suggests that a 1-mm expansion is safe and potentially has a lower risk of RN without compromising local control [15,38].

In regards to resection cavity volume dynamics, a retrospective study by Atalar et al. examining 68 cavities in 63 patients demonstrated that the median resection cavity volume was $29 \%$ smaller in volume compared to the pre-operative tumor volume $(10.1 \mathrm{~mL}$ vs. $14.5 \mathrm{~mL}$ ) [50]. However, the uniform expansion of $2 \mathrm{~mm}$ increased the median target volume to $15.6 \mathrm{~mL}$ and essentially negated the benefit of reduced target volume following resection [50]. In the 31 patients who had immediate post-operative and SRS planning MRI available for review in this study, there was no significant difference between cavity volumes, with approximately 4-5 weeks between imaging [50]. 
Nonetheless, there is conflicting data regarding the amount of resection cavity volume change between immediate post-operative imaging and pre-treatment SRS imaging. Contrary to the results from Atalar et al., a retrospective study by Jarvis et al. examining 43 cavities in 41 patients demonstrated that only $46.5 \%$ of resection cavities remained stable in size, with $23.3 \%$ decreasing in size by more than $2 \mathrm{~mL}$ and $30.2 \%$ increasing in size by more than $2 \mathrm{~mL}$ [51]. Similar findings were demonstrated in a retrospective analysis by Scharl et al., which examined 57 cavities in 57 patients found that the mean resection cavity volume decreased by $23.4 \%$ and decreased in $79.1 \%$ of cases examined [52]. Moreover, this study also found that the resection cavity continued to shrink between planning MRI and first follow-up MRI, with an average volume decrease of 20.7\% [52].

Interestingly, the amount of T2 edema on immediate post-operative MRI has been demonstrated to be associated with a decrease in resection cavity volume on SRS planning imaging for cavities less than $4.0 \mathrm{~cm}$ in maximum diameter [53]. Of the 37 patients included in this study, 22 patients had resection cavities $>2.0 \mathrm{~cm}$ in maximal diameter. The majority of patients $(n=24)$ had $>2.0 \mathrm{~cm}$ maximal dimension of vasogenic edema (defined by T2 hyperintensity). This study determined that vasogenic edema measuring $>1.5 \mathrm{~cm}$ was the factor that predicted a decrease in cavity size by $10 \%$ or more [53]. In sum, given the higher likelihood of large brain metastases presenting with significant vasogenic edema, the potential for cavity involution and the extent of post-operative edema potentially predicting this process are important concepts to consider when reviewing post-operative or treatment planning MRI and trying to determine SRS or HSRT for large resection cavities.

\subsubsection{The Potential Benefits of Pre-Operative SRS}

The potential advantages of pre-operative SRS are as follows: (1) tumor is easy to identify and contour; (2) expansion margin is not required for target delineation uncertainty; (3) dose is often reduced by $20 \%$ given better oxygenation of intact tumor and planned surgery; and (4) there is potentially a reduction in leptomeningeal disease (LMD) risk following surgery [37]. When treating intact brain metastases with planned pre-operative SRS, the expansion margin is typically $0-1 \mathrm{~mm}$ with no utilization of volumetric expansion (i.e., GTV = PTV) being most commonly employed $[37,49,54]$. The lack of PTV margin and radiation dose reduction with planned pre-operative SRS reduces the volume of healthy brain tissue receiving 10-12 Gy, which are volumes that have been associated with increased RN $[10,27,29,37,49,55,56]$. Prabhu et al. reported a 1-year RN risk of approximately $5 \%$ and 2-year RN risk of $8.1-9 \%$ with pre-operative SRS delivered within $48 \mathrm{~h}$ of surgical resection [36,49]. Additionally, Patel et al. reported 2-year symptomatic RN rates of $4.9 \%$ for pre-operative SRS, which was significantly less than the $16.4 \%$ rate for post-operative SRS $(p=0.010)$ [45].

Regarding the potential decrease in risk of LMD, a multi-institutional retrospective study by Patel et al. found post-operative SRS to be associated with a significantly higher 2-year rate of LMD compared to pre-operative SRS (16.6\% vs. $3.2 \% ; p=0.010)$ when examining 180 patients with 189 brain metastases who underwent resection and either pre-operative or post-operative SRS [45]. Furthermore, a separate multi-institutional retrospective study by Patel et al. found that patients receiving pre-operative SRS (66 patients with 71 lesions) had similar 2-year LMD rates (Pre-op SRS: 3.5\% vs. WBRT: 9\%) compared to patients receiving post-operative WBRT (36 patients with 42 cavities) [46].

Multiple studies have demonstrated that surgical resection of brain metastases is associated with higher rates of LMD compared to SRS alone [26,40-42]. These studies estimate the risk of LMD following SRS alone to be 5-6.2\% [40-42]. Modern series examining rates of 1-year LMD with post-operative SRS estimate the rate to be $7.2-30 \%$ with the large heterogeneity potentially due to the variable definitions of LMD versus focal dural recurrence within the resection cavity $[11,15,43,44,57]$. LMD following resection is thought to be due to an increased risk of tumor spillage into the CSF at the time of surgery, which was not clinically relevant previously when post-operative WBRT was routinely used and potentially sterilized the intracranial CSF [46]. Additional risk factors for LMD 
post-operatively are breast cancer histology, piecemeal resection, posterior fossa location, multiple brain metastases, hemorrhagic features, and cystic features $[43,45,58-61]$.

Another factor potentially contributing to the high rates of LMD with post-operative SRS is the use of a uniform 1-2-mm expansion without covering surgical tract or preoperatively involved dura and venous sinus structures. This concern was addressed in the recent consensus contouring guidelines for post-operative SRS [62]. The authors recommended the CTV cover the entire resection cavity and surgical tract. Additionally, they recommended an additional 5-10-mm margin along the bone flap if the dura was involved pre-operative (1-5-mm margin if not involved pre-operatively) as well as a $1-5 \mathrm{~mm}$ margin along the venous sinus if the tumor abutted the sinus pre-operatively.

Reviewing these guidelines in the context of the two recently published clinical trials evaluating post-operative SRS against observation or post-operative WBRT, it should be noted that the 1-year rate of LMD for post-operative SRS was 7.2\% in N107C trial compared to $28 \%$ in the Mahajan et al. study [11,15]. Of note, as discussed above, the N107C trial utilized a 2-mm PTV margin compared to the 1-mm PTV margin used by Mahajan et al., which suggests that even small margin modifications could potentially influence LMD rates in addition to $\mathrm{RN}$ rates. However, the risk of 1 -year $\mathrm{RN}$ was $<5 \%$ in both trials $[11,15]$. Unfortunately, large brain metastases often result in large resection cavities and additional coverage of the surgical tract and involved dura or venous structures results in a large target volume, which necessitates a lower prescription dose.

The N107C trial allowed the maximum resection cavity diameter to be up to $5 \mathrm{~cm}$ compared to Mahajan et al. excluding resection cavities with diameter $>4 \mathrm{~cm}$ and having a median cavity volume of $8.9 \mathrm{~mL}$ (median volume not listed for N107C) [11,15]. The lower than expected 1-year local control rate of the N107C trial (61.8\% vs. expected $70-80 \%)$ could be attributed to the uniform 2-mm expansion with lack of surgical tract coverage or prescription doses with too low of biologically effective doses for large resection cavities (17 Gy for 8.0-14.3 mL; 15 Gy for 14.4-19.9 mL; 12 Gy for $30 \mathrm{~mL}$ or more) [11]. However, the data by Mahajan et al. demonstrates a 1-year local control rate of $72 \%$ utilizing only a 1-mm expansion, but the 1-year local control rate drops to $40-46 \%$ for resection cavities $>2.5 \mathrm{~cm}$ in maximum diameter ( $8.4 \mathrm{~mL}$ using spherical modeling) [15]. The authors of the N107C trial also comment that the local control rate could have been lower than expected due to SRS post-treatment change being falsely called recurrence [11].

Ultimately, pre-operative SRS provides a unique opportunity to provide equivalent local control, or possibly improved control for large tumors, with potentially decreased risk of RN and LMD due to the ability to reduce the dose by approximately $20 \%$, sterilize the surgical bed pre-operative, and utilize little-to-no expansion. However, when considering pre-operative SRS or HSRT, it should be noted that the majority of the available data comes from a small group of authors with a shared database of prospectively and retrospectively obtained end points. These results may not be widely generalizable and may better reflect the specific results of the authors' community and academic practices. Nonetheless, the preliminary results are promising and will hopefully spur further clinical research on this topic.

\subsubsection{The Pitfalls of Pre-Operative SRS and Advantage of Post-Operative SRS}

The main pitfalls of pre-operative SRS and advantages of post-operative SRS are in the circumstances of benign surgical pathology, subtotal resection, and neurologic symptoms at presentation [37]. In the cases of benign surgical pathology, the patient could be spared from unnecessary radiation should the post-operative SRS paradigm be employed. In the initial study by Patchell et al. examining the benefit of surgery compared to WBRT, a total of 6 patients (11\%) from the initially recruited cohort of 54 patients were excluded because final surgical pathology was benign [63]. Improvements in MRI and functional imaging have undoubtedly improved our ability to determine recurrent or metastatic disease from benign lesions, but the rate of false detection will likely never be $0 \%$. 
In the event of a subtotal resection, post-operative radiation therapy allows the opportunity to treat the residual disease definitively with an adequate dose. For cases of subtotal resection following pre-operative SRS, the scenario is complicated by the commonly utilized $20 \%$ dose reduction owing to the theoretical improved oxygenation of intact metastases. While the reduced dose regimen delivered pre-operatively is considered sub-therapeutic for definitive treatment, the current consensus recommendation is for surveillance and consideration of re-irradiation as a last resort for continued progression [37]. Nonetheless, cases of subtotal resection are difficult clinical scenarios with worse outcomes compared to GTR regardless of whether pre-operative or post-operative SRS is chosen [35,57].

Finally, it is not uncommon for patients with large brain metastases to experience mass effect and edema. In such situation, immediate relief of mass effect is necessary and preoperative SRS may not be suitable. Immediate surgical resection to relieve the mass effect followed by postoperative SRS is the more appropriate treatment.

\section{The Appropriate Use of Hypofractionated Stereotactic Radiation Therapy (HSRT)}

As discussed above, the control rate for large brain metastases is poor, with 1-year and 2-year rates between $40 \%$ and 50\% with post-operative SRS [15,19,30-32,64]. Moreover, the volume of healthy brain tissue receiving $12 \mathrm{~Gy}$ (V12 Gy) has been correlated with risk of $\mathrm{RN}$, especially for volumes $>10 \mathrm{~mL}$, with $\mathrm{RN}$ risks ranging between $15 \%$ and $55 \%[24,25,27,65,66]$. HSRT provides the ability to improve local control and reduce the risk of RN by taking advantage of the manipulation of the biologically effective dose (BED) that fractionation can have on early and late responding tissues as described in the linear-quadratic model [67]. Table 2 demonstrates this effect on BED for the commonly employed fractionation schemes in SRS and HSRT.

Table 2. Commonly employed SRS and HSRT schemes and their associated BED for early and late responding tissues. BED Gy $y_{10}$ represents the BED for early responding tissue such as tumor cells. BED Gy, represents the BED for late responding tissue, such as healthy brain cells. Gy = Gray, $\mathrm{fx}=$ fraction(s).

\begin{tabular}{ccc}
\hline Regimen & BED Gy 10 $_{\mathbf{0}}$ & BED Gy $_{\mathbf{2}}$ \\
\hline $30 \mathrm{~Gy} / 5 \mathrm{fx}$ & 48.0 & 120.0 \\
$27 \mathrm{~Gy} / 3 \mathrm{fx}$ & 51.3 & 148.5 \\
$18 \mathrm{~Gy} / 1 \mathrm{fx}$ & 50.4 & 180.0 \\
$16 \mathrm{~Gy} / 1 \mathrm{fx}$ & 41.6 & 144.0 \\
$14 \mathrm{~Gy} / 1 \mathrm{fx}$ & 33.6 & 112.0 \\
$12 \mathrm{~Gy} / 1 \mathrm{fx}$ & 26.4 & 84.0 \\
\hline
\end{tabular}

Interest has increased for the utilization of HSRT, and multiple retrospective studies have been published examining the rates of local control and RN for HSRT [26,28,57,68-72]. The 1-year local control rate for HSRT following resection of a large brain metastasis ranges widely between $65 \%$ and $95 \%$ [26,57,68-72]. The rates of RN with HSRT range from $5 \%$ to $25 \%$ for the same cohort of patients with resected large brain metastases [26,57,72]. Recently published guidelines updating the radiation dose-volume tolerances of brain tissue for novel 3-fraction HSRT regimens reported the volume of normal brain tissue receiving $18 \mathrm{~Gy}$ (V18 Gy) as less than $30 \mathrm{~mL}$ and the volume of normal brain tissue receiving $23 \mathrm{~Gy}$ (V23 Gy) as less than $7 \mathrm{~mL}$ kept RN risk below $10 \%$ on a pooled analysis of available studies [65].

In regards to the optimal resection cavity volume or tumor diameter to begin considering HSRT over SRS, there is variability in the literature reporting the volume (or maximum diameter) cutoff where HSRT is superior in terms of local control or RN. From an early report by Schlienger et al., HSRT is preferable to SRS for tumors $>2 \mathrm{~cm}$ in maximum diameter due to superior local control and decreased RN risk [73]. Multiple other studies suggest the decrease in local control becomes significant for SRS at pre-operative maximum tumor diameter $>3 \mathrm{~cm}$ or resection cavity volume $>15 \mathrm{~mL}[15,38,74]$. 
A meta-analysis by Akanda et al. examined the impact of dose, fractionation, treatment volume margin, and time to SRS on 1-year local control for post-operative SRS compared to post-operative HSRT [75]. However, this analysis did not examine the effect of resection cavity size. The mean 1-year local control rate was $80 \%$ across the 24 studies that utilized post-operative SRS. There was no significant difference in mean 1-year local control when examining median SRS dose $<18$ Gy vs. $\geq 18$ Gy ( $80 \%$ vs. $81 \%$ ). In the 14 studies that utilized post-operative HSRT, the mean 1-year local control was $87.3 \%$, which was significantly better than post-operative SRS ( $p=0.021)$. There was no significant difference in mean 1-year local control when comparing the 21 studies that utilized an expansion margin compared to the 5 studies that did not employ an expansion on the resection cavity. The overall rate of $\mathrm{RN}$ was $6.9 \%$ for the 36 studies that reported this outcome. The overall rate of LMD was $12.6 \%$ for the 22 studies that reported this outcome.

A meta-analysis by Lehrer et al. that specifically looked at brain metastases $>2 \mathrm{~cm}$ demonstrated a significantly reduced risk of RN for HSRT compared to SRS for tumors 2-3 cm maximum diameter with a median cavity volume of $9.8 \mathrm{~mL}(7.3 \%$ vs. $23.1 \%$; $p=0.003$ ) and provided a similar rate of 1-year local control (HSRT: $92.9 \%$ vs. SRS: $77.1 \%$; $p=0.18$ ) [26]. However, for tumors $>3 \mathrm{~cm}$ (median resection cavity volume of $17.5 \mathrm{~mL}$ ), there was no significant benefit for HSRT in the definitive or post-operative setting in terms of RN [26]. They did note a trend towards significance in the post-operative setting benefitting HSRT compared to SRS for 1-year local control in tumors $>3 \mathrm{~cm}$ (HSRT: $85.7 \%$ vs. SRS: $62.4 \% ; p=0.13)$ with similar rates of RN (7.3\% vs. $7.5 \%)$ [26].

In comparing these results to those of the meta-analysis by Akanda et al., the 1-year local control for HSRT in the 2-3-cm group and $>3-\mathrm{cm}$ group are similar to the mean 1-year local control rate of $87 \%$. However, the 1-year local control for SRS in the $>3$-cm group is noticeably less than the mean 1-year local control rate of $80 \%$ demonstrated by Akanda et al. This discrepancy, the lack of dose effect on mean 1-year local control in the data from Akanda et al., and the similar 1-year local control rates between the HSRT groups suggests that the SRS trials included in the Akanda et al. analysis likely treated smaller resection cavities while the HSRT trials preferentially included larger resection cavities.

More recently, a single institution prospective registry study by Faruqi et al. examined asymptomatic and symptomatic RN in 187 patients with 118 surgical cavities and 132 intact metastases who were treated with 5-fraction HSRT using a 2-mm PTV expansion [76]. The median dose was 30 Gy (range: 20-35 Gy), and the median follow up was 12 months. The median resection cavity volume was $12.7 \mathrm{~mL}$ (maximum dimension $2.9 \mathrm{~cm}$ using a spherical model), and the median intact metastasis $2.9 \mathrm{~mL}$ (maximum dimension $1.8 \mathrm{~cm}$ using a spherical model). The median resection cavity PTV was $24.9 \mathrm{~mL}$, and the median intact metastasis PTV was $7.7 \mathrm{~mL}$. Overall, $64 \%$ of intact metastases or cavities were $>2 \mathrm{~cm}$ in maximum dimension.

The $\mathrm{RN}$ rates in this patient cohort were $21.2 \%$ for asymptomatic $\mathrm{RN}$ and $10.8 \%$ for symptomatic RN [76]. The median time to asymptomatic RN was 7.9 months and 7 months for symptomatic RN. The 1-year RN risk for resection cavities was $12 \%$ compared to the 1 -year RN risk of $22 \%$ for intact metastases. Multivariate analysis revealed significantly increased risk of $\mathrm{RN}$ for intact metastases compared to resection cavities (OR 3.5; $p=0.001$ ) and for single metastasis treatment plans compared to multiple metastases treated in the plan (OR 3.7; $p=0.001$ ). The significant risk factors that predicted increased risk for symptomatic RN were prior SRS (OR 8.7; $p=0.037$ ) or WBRT (OR 7.7; $p=0.009)$ to the target. For resection cavities, only targeted immunotherapies within 1 month of treatment significantly increased the risk of RN on multivariate analysis (OR 17.4; $p=0.018$ ).

Overall, this study demonstrated a 1-year local control of $84 \%$ for resection cavities and $78.2 \%$ for intact metastases [76]. Moreover, they demonstrated that a healthy brain volume minus the intact metastasis volume receiving $30 \mathrm{~Gy}$ (BMC30) was a significant risk factor for symptomatic RN with a threshold of $10.5 \mathrm{~mL}$ or more (OR 7.2; $p=0.02$ ). The 1-year symptomatic $\mathrm{RN}$ rate was $13 \%$ for BMC $30<10.5 \mathrm{~mL}$ and $61 \%$ for BMC30 of $10.5 \mathrm{~mL}$ or greater. Ultimately, they believe the higher rate of $\mathrm{RN}$ in the intact metastasis group 
was related to significantly increased exposure to prior WBRT (32\% vs. $13 \% ; p<0.001$ ) and targeted immunotherapies $(13 \%$ vs. $3 \% ; p<0.01)$ compared to the resection cavity cohort. They do not note any difference in radiation dose delivered between the intact metastases and resection cavities arms. However, they do recommend dose reduction from 30 to $27.5 \mathrm{~Gy}$ for intact metastases with BMC30 > $10 \mathrm{~mL}$.

Lastly, a multi-institutional retrospective analysis by Eitz et al. examining outcomes and prognostic factors for patients receiving post-operative HSRT was recently published and provides additional insight to what was learned from the Lehrer et al. meta-analysis. This large multi-institutional analysis of 558 patients with 581 resection cavities demonstrated 1-year local control of $84 \%$ for a median dose of 30 Gy over 5 fractions with a median resection cavity volume of $10.9 \mathrm{~mL}$ (max diameter $>2.6 \mathrm{~cm}$ using spherical modeling) and median PTV volume of $23.9 \mathrm{~mL}$ [57]. The 1-year rate of $\mathrm{RN}$ was $8.6 \%$ and 1-year rate of LMD was $13.1 \%$ [57]. On multivariate analysis, there was no significant difference in local control between PTV volumes $<23 \mathrm{~mL}$ or those $23 \mathrm{~mL}$ and greater [57]. There was durable 2-year and 3-year local control rates of 75\% and 71\%, respectively, and patients with a controlled primary tumor (HR 0.59; $p=0.02$ ) and a single brain metastases (HR 0.57; $p=0.03$ ) had significantly improved local control on multivariate analysis. Lastly, multivariate analysis noted a significant detriment on overall survival when HSRT was delivered 22-33 days after resection compared to 0-21 days after resection (HR 1.50; $p=0.02$ ), but there was no significant difference in local control when comparing these two groups [57].

The similar 1-year local control results between the Lehrer et al. (85.7-92.9\%), Akanda et al. (87.3\%), Faruqi et al. (84\%), and Eitz et al. (84\%) are very promising for HSRT despite varied fractionation schemes and median resection cavity volumes $(9.8-18.5 \mathrm{~mL}$ vs. unknown vs. $12.7 \mathrm{~mL}$ vs. $10.9 \mathrm{~mL}$ ). Multiple trials have examined the optimal dose fractionation scheme for HSRT in patients with large brain metastases [76-80]. A BED Gy10 of $50 \mathrm{~Gy}$ or more appears to provide significantly improved local control [78]. However, lower BED regimens have been demonstrated to provide similar control.

Specifically, a retrospective study by Keller et al. examined 181 patients with 189 resection cavities who received $23.1 \mathrm{~Gy}$ over 3 fractions to PTV prescribed to the $70 \%$ isodose line [81]. A 2-mm expansion was used to create the PTV, and the BED Gy 10 of this regimen is 40.9 Gy. The 1 -year local control was $88.2 \%$, and the 1 -year RN risk was $5.4 \%$. While $54 \%$ of the 189 lesion were $\geq 3 \mathrm{~cm}$ pre-operatively, the median treated resection cavity volume was $7.6 \mathrm{~mL}$. This volume is noticeably smaller than the volumes for the meta-analysis and retrospective studies listed above, which could explain the good outcomes with a lower BED Gy10 regimen.

As such, when choosing 3- or 5-fraction regimens to meet the recommended BED goal, the radiation oncologist must not only consider the resection cavity size but also consider the volume of healthy brain irradiated as well as the suggested brainstem and optic apparatus constraints. As mentioned above, limiting the healthy brain exposure to the following constraints has been shown to keep RN risk reasonably low: V18 $<30 \mathrm{~mL}$ and V23 $<7 \mathrm{~mL}$ for 3-fraction HSRT regimens as well as BMC $30<10.5 \mathrm{~mL}$ for 5-fraction regimens $[65,76]$. Additionally, the suggested maximum dose to the optic apparatus is 21-25 Gy in 5 fractions and 15-18 Gy over 3 fractions [79,80,82]. The suggested maximum dose to the brainstem is $31 \mathrm{~Gy}$ in 5 fractions and 23 Gy over 3 fractions [79,80,82]. To best balance these constraint goals with the above-mentioned BED goal, we have chosen 27 Gy over 3 fractions and 30 Gy over 5 fractions as the regimens with the best risk-to-benefit ratio and with the most robust amount of data to support their use. Furthermore, we would discourage the use of SRS to 15 Gy or less for large tumors or resection cavities and would instead recommend the above mentioned 3- or 5-fraction regimens.

For determining the best measurement to appraise when considering SRS or HRST, volumetric measurements of tumors or resection cavities are likely more valuable than maximum dimension measurements given the often non-spherical and variable shapes of resection cavities or intact metastases. Furthermore, recent and ongoing trials, namely N107C and A071801, have utilized volumetric measurements to guide prescription doses. 
Lastly, radiation dose constraints are often volumetric, and as discussed above, volumetric constraints for healthy brain predicting RN risk in the context of HSRT have recently been proposed for 3-fraction regimens (V18 $<30 \mathrm{~mL}$ and $\mathrm{V} 23<7 \mathrm{~mL}$ ) as well as for 5-fraction regimens $(\mathrm{BMC} 30<10.5 \mathrm{~mL})[65,76]$.

We have provided an algorithm to help guide the optimal treatment of patients presenting with a large brain metastasis and the additional following criteria: (1) no more than 4 brain metastases; (2) a KPS of $60 \%$ or greater; (3) unresected metastasis $<4.0 \mathrm{~cm}$ in maximum dimension; (4) resection cavity $<5.0 \mathrm{~cm}$ in maximum dimension; and (5) the patient is medically fit for surgical resection (Figure 1). These criteria are similar to the current inclusion criteria for the ongoing Alliance A071801 trial examining local control in SRS compared to HSRT for large brain metastases. Until the results of the A071801 trial are available, we will have to rely on expert consensus and guidance utilizing the currently existing data outlined above. For patients unable to undergo surgery and who have 5-10 brain metastases with cumulative tumor volume $<7 \mathrm{~mL}$, we recommend SRS or HSRT alone per current consensus guidelines $[10,83]$.

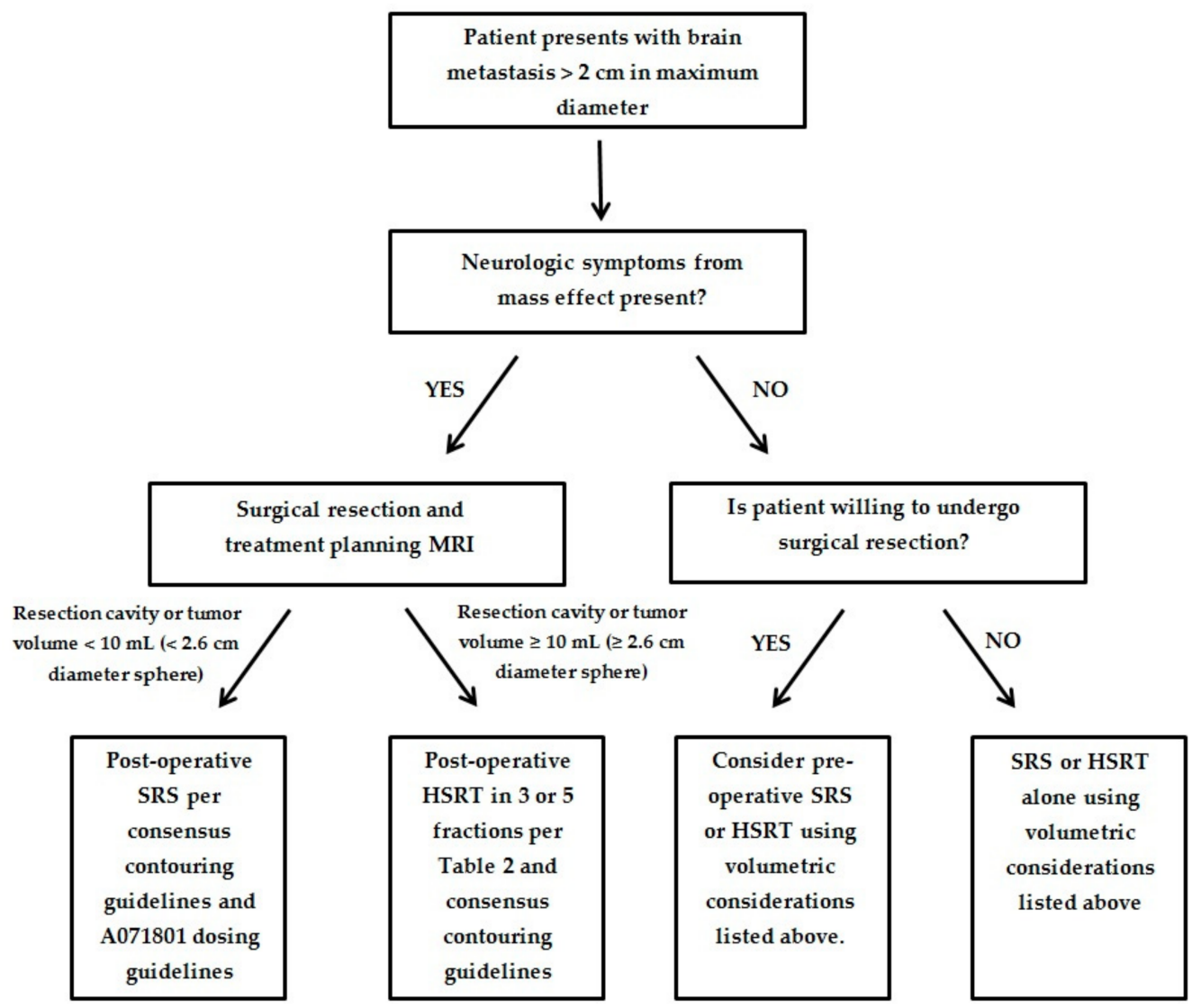

Figure 1. Proposed algorithm for management of patients with large brain metastasis.

Lastly, in regard to the optimal duration between resection and SRS or HSRT, the A071801 protocol requires gross total resection and post-operative brain MRI within 30 days of pre-registration. The meta-analysis by Akanda et al. noted similar mean 1-year local control values for SRS within 30 days of resection or after 30 days of resection (85.1\% vs. 82.7\%) [75]. Moreover, the large retrospective study by Eitz et al. did not find a significant difference in local control on multivariate analysis when comparing 22-33 days between resection and HSRT to $0-21$ days or $\geq 34$ days [57]. The significantly decreased OS in the 22-33-day group could have been related to patients with post-operative complications or poor performance status recovering more slowly from surgery and experiencing worse survival independent of treatment timing. As such, we recommend post-operative brain 
MRI 3 to 4 weeks following resection to allow for optimal recovery and potential decrease in resection cavity size. Post-operative SRS or HSRT should occur within days of postoperative brain MRI.

\section{Conclusions}

The management of large brain metastases often presents a unique clinical challenge for oncologists to provide treatment with the best opportunity for disease control while limiting the long-term toxicity from treatment. These patients often present with neurologic symptoms that require expeditious treatment that must also be balanced against the potential consequences of surgery and radiation therapy-namely, leptomeningeal dissemination and radionecrosis. Early data suggests that HSRT and pre-operative SRS or HSRT are promising techniques to improve local control and minimize toxicity for patients with large brain metastases. We look forward to the results of A071801 and other future prospective randomized controlled trials examining these techniques. We recommend 3- or 5 -fraction regimens in lieu of SRS delivering $15 \mathrm{~Gy}$ or less. We have provided a comparative dose-fractionation table and a management algorithm based on the current data to help guide treatment until more information is available.

Author Contributions: T.G. and S.S.L. devised the concept for this manuscript and created the manuscript's original draft. V.A.V., S.E.C., B.V., A.P.P., M.F., K.J.R., T.J.C.W., A.S., S.T.C., J.H.S., E.L.C., and R.G.E. critically reviewed the manuscript's content, provided essential revisions, and offered expert commentary regarding the reference articles that shaped the manuscript's content. All listed authors reviewed the manuscript and provided meaningful contributions to its creation. All authors have read and agreed to the published version of the manuscript.

Funding: This research received no external funding.

Institutional Review Board Statement: Not applicable.

Informed Consent Statement: Not applicable.

Conflicts of Interest: Matthew Foote has received Honorarium and Research support from Elekta $\mathrm{AB}$ and is a Consultant to Varian; Kristin J. Redmond reports the following: Elekta AB- research funding, travel expenses; Accuray- research funding, travel expenses, honorarium for speaking engagement; Branlab- travel expenses; BioMimetix- data safety monitoring board; Tony Wang reports personal fees and non-financial support from AbbVie, personal fees and non-financial support from RTOG Foundation, during the conduct of the study; personal fees and non-financial support from AbbVie, personal fees from AstraZeneca, personal fees from Cancer Panels, personal fees from Doximity, personal fees and non-financial support from Elekta, personal fees and non-financial support from Merck, personal fees and non-financial support from Novocure, personal fees and nonfinancial support from RTOG Foundation, personal fees from Rutgers, personal fees from University of Iowa, personal fees from Wolters Kluwer, outside the submitted work; Arjun Sahgal reports the following: Advisor/consultant with AbbVie, Merck, Roche, Varian (Medical Advisory Group), Elekta (Gamma Knife Icon), BrainLAB, and VieCure (Medical Advisory Board); Board Member: International Stereotactic Radiosurgery Society (ISRS); Co-Chair: AO Spine Knowledge Forum Tumor; Past educational seminars with Elekta AB, Accuray Inc., Varian (CNS Teaching Faculty), BrainLAB, Medtronic Kyphon; Research grant with Elekta AB; Travel accommodations/expenses by Elekta, Varian, BrainLAB; Member of the Elekta MR Linac Research Consortium, Elekta Spine, Oligometastases and Linac Based SRS Consortia; Samuel T. Chao has received an honorarium from Varian Medical Systems; John H. Suh has received honorarium from Philips and Novocure as a scientific advisory board member; Simon S. Lo is a member of the Elekta Gamma Knife ICON Expert Group. All other authors have no conflict of interest to declare.

\section{References}

1. Cagney, D.N.; Martin, A.M.; Catalano, P.J.; Redig, A.J.; Lin, N.U.; Lee, E.Q.; Wen, P.Y.; Dunn, I.F.; Bi, W.L.; Weiss, S.E.; et al. Incidence and prognosis of patients with brain metastases at diagnosis of systemic malignancy: A population-based study. Neuro-Oncology 2017, 19, 1511-1521. [CrossRef]

2. Stelzer, K.J. Epidemiology and prognosis of brain metastases. Surg. Neurol. Int. 2013, 4, S192-S202. [CrossRef] [PubMed] 
3. Barnholtz-Sloan, J.S.; Sloan, A.E.; Davis, F.G.; Vigneau, F.D.; Lai, P.; Sawaya, R.E. Incidence proportions of brain metastases in patients diagnosed (1973 to 2001) in the Metropolitan Detroit Cancer Surveillance System. J. Clin. Oncol. 2004, 22, $2865-2872$. [CrossRef] [PubMed]

4. Nayak, L.; Lee, E.Q.; Wen, P.Y. Epidemiology of brain metastases. Curr. Oncol. Rep. 2012, 14, 48-54. [CrossRef]

5. Patchell, R.A. The management of brain metastases. Cancer Treat. Rev. 2003, 29, 533-540. [CrossRef]

6. Brastianos, H.C.; Nguyen, P.; Sahgal, A.; Eisenhauer, E.A.; Baetz, T.; Hanna, T.P. Association of Innovations in Radiotherapy and Systemic Treatments With Clinical Outcomes in Patients With Melanoma Brain Metastasis From 2007 to 2016. JAMA Netw. Open 2020, 3, e208204. [CrossRef] [PubMed]

7. Lee, S.; Ahn, H.K.; Park, Y.H.; Nam, D.H.; Lee, J.I.; Park, W.; Choi, D.H.; Huh, S.J.; Park, K.T.; Ahn, J.S.; et al. Leptomeningeal metastases from breast cancer: Intrinsic subtypes may affect unique clinical manifestations. Breast Cancer Res. Treat. 2011, 129, 809-817. [CrossRef]

8. Steeg, P.S.; Camphausen, K.A.; Smith, Q.R. Brain metastases as preventive and therapeutic targets. Nat. Rev. Cancer 2011, 11, 352-363. [CrossRef] [PubMed]

9. Tsao, M.N.; Rades, D.; Wirth, A.; Lo, S.S.; Danielson, B.L.; Gaspar, L.E.; Sperduto, P.W.; Vogelbaum, M.A.; Radawski, J.D.; Wang, J.Z.; et al. Radiotherapeutic and surgical management for newly diagnosed brain metastasis(es): An American Society for Radiation Oncology evidence-based guideline. Pract. Radiat. Oncol. 2012, 2, 210-225. [CrossRef] [PubMed]

10. Milano, M.T.; Chiang, V.L.S.; Soltys, S.G.; Wang, T.J.C.; Lo, S.S.; Brackett, A.; Nagpal, S.; Chao, S.; Garg, A.K.; Jabbari, S.; et al. Executive Summary from American Radium Society's Appropriate Use Criteria on Neurocognition after stereotactic radiosurgery for multiple brain metastases. Neuro-Oncology 2020. [CrossRef]

11. Brown, P.D.; Ballman, K.V.; Cerhan, J.H.; Anderson, S.K.; Carrero, X.W.; Whitton, A.C.; Greenspoon, J.; Parney, I.F.; Laack, N.N.I.; Ashman, J.B.; et al. Postoperative stereotactic radiosurgery compared with whole brain radiotherapy for resected metastatic brain disease (NCCTG N107C/CEC·3): A multicentre, randomised, controlled, phase 3 trial. Lancet Oncol. 2017, 18, 1049-1060. [CrossRef]

12. Brown, P.D.; Jaeckle, K.; Ballman, K.V.; Farace, E.; Cerhan, J.H.; Anderson, S.K.; Carrero, X.W.; Barker, F.G., 2nd; Deming, R.; Burri, S.H.; et al. Effect of Radiosurgery Alone vs Radiosurgery With Whole Brain Radiation Therapy on Cognitive Function in Patients With 1 to 3 Brain Metastases: A Randomized Clinical Trial. JAMA 2016, 316, 401-409. [CrossRef] [PubMed]

13. Chang, E.L.; Wefel, J.S.; Hess, K.R.; Allen, P.K.; Lang, F.F.; Kornguth, D.G.; Arbuckle, R.B.; Swint, J.M.; Shiu, A.S.; Maor, M.H.; et al. Neurocognition in patients with brain metastases treated with radiosurgery or radiosurgery plus whole-brain irradiation: A randomised controlled trial. Lancet Oncol. 2009, 10, 1037-1044. [CrossRef]

14. Chow, E.; Davis, L.; Holden, L.; Tsao, M.; Danjoux, C. Prospective assessment of patient-rated symptoms following whole brain radiotherapy for brain metastases. J. Pain Symptom Manag. 2005, 30, 18-23. [CrossRef] [PubMed]

15. Mahajan, A.; Ahmed, S.; McAleer, M.F.; Weinberg, J.S.; Li, J.; Brown, P.; Settle, S.; Prabhu, S.S.; Lang, F.F.; Levine, N.; et al. Post-operative stereotactic radiosurgery versus observation for completely resected brain metastases: A single-centre, randomised, controlled, phase 3 trial. Lancet Oncol. 2017, 18, 1040-1048. [CrossRef]

16. Soffietti, R.; Kocher, M.; Abacioglu, U.M.; Villa, S.; Fauchon, F.; Baumert, B.G.; Fariselli, L.; Tzuk-Shina, T.; Kortmann, R.D.; Carrie, C.; et al. A European Organisation for Research and Treatment of Cancer phase III trial of adjuvant whole-brain radiotherapy versus observation in patients with one to three brain metastases from solid tumors after surgical resection or radiosurgery: Quality-of-life results. J. Clin. Oncol. 2013, 31, 65-72. [CrossRef] [PubMed]

17. Angelov, L.; Mohammadi, A.M.; Bennett, E.E.; Abbassy, M.; Elson, P.; Chao, S.T.; Montgomery, J.S.; Habboub, G.; Vogelbaum, M.A.; Suh, J.H.; et al. Impact of 2-staged stereotactic radiosurgery for treatment of brain metastases $\geq 2 \mathrm{~cm}$. J. Neurosurg. 2018, 129, 366-382. [CrossRef] [PubMed]

18. Choi, C.Y.; Chang, S.D.; Gibbs, I.C.; Adler, J.R.; Harsh, G.R.T.; Atalar, B.; Lieberson, R.E.; Soltys, S.G. What is the optimal treatment of large brain metastases? An argument for a multidisciplinary approach. Int. J. Radiat. Oncol. Biol. Phys. 2012, 84, 688-693. [CrossRef] [PubMed]

19. Han, J.H.; Kim, D.G.; Chung, H.T.; Paek, S.H.; Park, C.K.; Jung, H.W. Radiosurgery for large brain metastases. Int. J. Radiat. Oncol. Biol. Phys. 2012, 83, 113-120. [CrossRef]

20. Lee, C.C.; Yen, C.P.; Xu, Z.; Schlesinger, D.; Sheehan, J. Large intracranial metastatic tumors treated by Gamma Knife surgery: Outcomes and prognostic factors. J. Neurosurg. 2014, 120, 52-59. [CrossRef] [PubMed]

21. Murai, T.; Ogino, H.; Manabe, Y.; Iwabuchi, M.; Okumura, T.; Matsushita, Y.; Tsuji, Y.; Suzuki, H.; Shibamoto, Y. Fractionated stereotactic radiotherapy using CyberKnife for the treatment of large brain metastases: A dose escalation study. Clin. Oncol. (R. Coll. Radiol) 2014, 26, 151-158. [CrossRef]

22. Navarria, P.; Pessina, F.; Cozzi, L.; Ascolese, A.M.; De Rose, F.; Fogliata, A.; Franzese, C.; Franceschini, D.; Tozzi, A.; D’Agostino, G.; et al. Hypo-fractionated stereotactic radiotherapy alone using volumetric modulated arc therapy for patients with single, large brain metastases unsuitable for surgical resection. Radiat. Oncol. 2016, 11, 76. [CrossRef] [PubMed]

23. Sneed, P.K.; Mendez, J.; Vemer-van den Hoek, J.G.; Seymour, Z.A.; Ma, L.; Molinaro, A.M.; Fogh, S.E.; Nakamura, J.L.; McDermott, M.W. Adverse radiation effect after stereotactic radiosurgery for brain metastases: Incidence, time course, and risk factors. J. Neurosurg. 2015, 123, 373-386. [CrossRef] [PubMed] 
24. Blonigen, B.J.; Steinmetz, R.D.; Levin, L.; Lamba, M.A.; Warnick, R.E.; Breneman, J.C. Irradiated volume as a predictor of brain radionecrosis after linear accelerator stereotactic radiosurgery. Int. J. Radiat. Oncol. Biol. Phys. 2010, 77, 996-1001. [CrossRef] [PubMed]

25. Korytko, T.; Radivoyevitch, T.; Colussi, V.; Wessels, B.W.; Pillai, K.; Maciunas, R.J.; Einstein, D.B. 12 Gy gamma knife radiosurgical volume is a predictor for radiation necrosis in non-AVM intracranial tumors. Int. J. Radiat. Oncol. Biol. Phys. 2006, 64, 419-424. [CrossRef] [PubMed]

26. Lehrer, E.J.; Peterson, J.L.; Zaorsky, N.G.; Brown, P.D.; Sahgal, A.; Chiang, V.L.; Chao, S.T.; Sheehan, J.P.; Trifiletti, D.M. Single versus Multifraction Stereotactic Radiosurgery for Large Brain Metastases: An International Meta-analysis of 24 Trials. Int. J. Radiat. Oncol. Biol. Phys. 2019, 103, 618-630. [CrossRef] [PubMed]

27. Minniti, G.; Clarke, E.; Lanzetta, G.; Osti, M.F.; Trasimeni, G.; Bozzao, A.; Romano, A.; Enrici, R.M. Stereotactic radiosurgery for brain metastases: Analysis of outcome and risk of brain radionecrosis. Radiat. Oncol. 2011, 6, 48. [CrossRef]

28. Minniti, G.; Esposito, V.; Clarke, E.; Scaringi, C.; Lanzetta, G.; Salvati, M.; Raco, A.; Bozzao, A.; Maurizi Enrici, R. Multidose stereotactic radiosurgery $(9 \mathrm{~Gy} \times 3)$ of the postoperative resection cavity for treatment of large brain metastases. Int. J. Radiat. Oncol. Biol. Phys. 2013, 86, 623-629. [CrossRef]

29. Varlotto, J.M.; Flickinger, J.C.; Niranjan, A.; Bhatnagar, A.K.; Kondziolka, D.; Lunsford, L.D. Analysis of tumor control and toxicity in patients who have survived at least one year after radiosurgery for brain metastases. Int. J. Radiat. Oncol. Biol. Phys. 2003, 57, 452-464. [CrossRef]

30. Chang, E.L.; Hassenbusch, S.J., 3rd; Shiu, A.S.; Lang, F.F.; Allen, P.K.; Sawaya, R.; Maor, M.H. The role of tumor size in the radiosurgical management of patients with ambiguous brain metastases. Neurosurgery 2003, 53, 272-280. [CrossRef]

31. Vogelbaum, M.A.; Angelov, L.; Lee, S.Y.; Li, L.; Barnett, G.H.; Suh, J.H. Local control of brain metastases by stereotactic radiosurgery in relation to dose to the tumor margin. J. Neurosurg. 2006, 104, 907-912. [CrossRef]

32. Yang, H.C.; Kano, H.; Lunsford, L.D.; Niranjan, A.; Flickinger, J.C.; Kondziolka, D. What factors predict the response of larger brain metastases to radiosurgery? Neurosurgery 2011, 68, 682-690. [CrossRef] [PubMed]

33. Kocher, M.; Soffietti, R.; Abacioglu, U.; Villà, S.; Fauchon, F.; Baumert, B.G.; Fariselli, L.; Tzuk-Shina, T.; Kortmann, R.D.; Carrie, C.; et al. Adjuvant whole-brain radiotherapy versus observation after radiosurgery or surgical resection of one to three cerebral metastases: Results of the EORTC 22952-26001 study. J. Clin. Oncol. 2011, 29, 134-141. [CrossRef] [PubMed]

34. Patchell, R.A.; Tibbs, P.A.; Regine, W.F.; Dempsey, R.J.; Mohiuddin, M.; Kryscio, R.J.; Markesbery, W.R.; Foon, K.A.; Young, B. Postoperative radiotherapy in the treatment of single metastases to the brain: A randomized trial. JAMA 1998, 280, 1485-1489. [CrossRef] [PubMed]

35. Quigley, M.R.; Bello, N.; Jho, D.; Fuhrer, R.; Karlovits, S.; Buchinsky, F.J. Estimating the additive benefit of surgical excision to stereotactic radiosurgery in the management of metastatic brain disease. Neurosurgery 2015, 76, 707-712. [CrossRef]

36. Prabhu, R.S.; Press, R.H.; Patel, K.R.; Boselli, D.M.; Symanowski, J.T.; Lankford, S.P.; McCammon, R.J.; Moeller, B.J.; Heinzerling, J.H.; Fasola, C.E.; et al. Single-Fraction Stereotactic Radiosurgery (SRS) Alone Versus Surgical Resection and SRS for Large Brain Metastases: A Multi-institutional Analysis. Int. J. Radiat. Oncol. Biol. Phys. 2017, 99, 459-467. [CrossRef]

37. Prabhu, R.S.; Miller, K.R.; Asher, A.L.; Heinzerling, J.H.; Moeller, B.J.; Lankford, S.P.; McCammon, R.J.; Fasola, C.E.; Patel, K.R.; Press, R.H.; et al. Preoperative stereotactic radiosurgery before planned resection of brain metastases: Updated analysis of efficacy and toxicity of a novel treatment paradigm. J. Neurosurg. 2018, 1-8. [CrossRef]

38. Jhaveri, J.; Chowdhary, M.; Zhang, X.; Press, R.H.; Switchenko, J.M.; Ferris, M.J.; Morgan, T.M.; Roper, J.; Dhabaan, A.; Elder, E.; et al. Does size matter? Investigating the optimal planning target volume margin for postoperative stereotactic radiosurgery to resected brain metastases. J. Neurosurg. 2018, 130, 797-803. [CrossRef]

39. Choi, C.Y.; Chang, S.D.; Gibbs, I.C.; Adler, J.R.; Harsh, G.R.T.; Lieberson, R.E.; Soltys, S.G. Stereotactic radiosurgery of the postoperative resection cavity for brain metastases: Prospective evaluation of target margin on tumor control. Int. J. Radiat. Oncol. Biol. Phys. 2012, 84, 336-342. [CrossRef]

40. Huang, A.J.; Huang, K.E.; Page, B.R.; Ayala-Peacock, D.N.; Lucas, J.T., Jr.; Lesser, G.J.; Laxton, A.W.; Tatter, S.B.; Chan, M.D. Risk factors for leptomeningeal carcinomatosis in patients with brain metastases who have previously undergone stereotactic radiosurgery. J. Neuro-Oncol. 2014, 120, 163-169. [CrossRef]

41. Johnson, M.D.; Avkshtol, V.; Baschnagel, A.M.; Meyer, K.; Ye, H.; Grills, I.S.; Chen, P.Y.; Maitz, A.; Olson, R.E.; Pieper, D.R.; et al. Surgical Resection of Brain Metastases and the Risk of Leptomeningeal Recurrence in Patients Treated With Stereotactic Radiosurgery. Int. J. Radiat. Oncol. Biol. Phys. 2016, 94, 537-543. [CrossRef] [PubMed]

42. Ma, R.; Levy, M.; Gui, B.; Lu, S.E.; Narra, V.; Goyal, S.; Danish, S.; Hanft, S.; Khan, A.J.; Malhotra, J.; et al. Risk of leptomeningeal carcinomatosis in patients with brain metastases treated with stereotactic radiosurgery. J. Neuro-Oncol. 2018, 136, 395-401. [CrossRef] [PubMed]

43. Foreman, P.M.; Jackson, B.E.; Singh, K.P.; Romeo, A.K.; Guthrie, B.L.; Fisher, W.S.; Riley, K.O.; Markert, J.M.; Willey, C.D.; Bredel, M.; et al. Postoperative radiosurgery for the treatment of metastatic brain tumor: Evaluation of local failure and leptomeningeal disease. J. Clin. Neurosci. Off. J. Neurosurg. Soc. Australas. 2018, 49, 48-55. [CrossRef] [PubMed]

44. Prabhu, R.S.; Turner, B.E.; Asher, A.L.; Marcrom, S.R.; Fiveash, J.B.; Foreman, P.M.; Press, R.H.; Patel, K.R.; Curran, W.J.; Breen, W.G.; et al. A Multi-Institutional Analysis of Presentation and Outcomes for Leptomeningeal Disease Recurrence After Surgical Resection and Radiosurgery for Brain Metastases. Neuro-Oncology 2019, 21, 1049-1059. [CrossRef] 
45. Patel, K.R.; Burri, S.H.; Asher, A.L.; Crocker, I.R.; Fraser, R.W.; Zhang, C.; Chen, Z.; Kandula, S.; Zhong, J.; Press, R.H.; et al. Comparing Preoperative With Postoperative Stereotactic Radiosurgery for Resectable Brain Metastases: A Multi-institutional Analysis. Neurosurgery 2016, 79, 279-285. [CrossRef]

46. Patel, K.R.; Burri, S.H.; Boselli, D.; Symanowski, J.T.; Asher, A.L.; Sumrall, A.; Fraser, R.W.; Press, R.H.; Zhong, J.; Cassidy, R.J.; et al. Comparing pre-operative stereotactic radiosurgery (SRS) to post-operative whole brain radiation therapy (WBRT) for resectable brain metastases: A multi-institutional analysis. J. Neuro-Oncol. 2017, 131, 611-618. [CrossRef]

47. Minniti, G.; Scaringi, C.; Paolini, S.; Lanzetta, G.; Romano, A.; Cicone, F.; Osti, M.; Enrici, R.M.; Esposito, V. Single-Fraction Versus Multifraction $(3 \times 9$ Gy) Stereotactic Radiosurgery for Large $(>2 \mathrm{~cm})$ Brain Metastases: A Comparative Analysis of Local Control and Risk of Radiation-Induced Brain Necrosis. Int. J. Radiat. Oncol. Biol. Phys. 2016, 95, 1142-1148. [CrossRef]

48. Zimmerman, A.L.; Murphy, E.S.; Suh, J.H.; Vogelbaum, M.A.; Barnett, G.H.; Angelov, L.; Ahluwalia, M.; Reddy, C.A.; Chao, S.T. Treatment of Large Brain Metastases With Stereotactic Radiosurgery. Technol. Cancer Res. Treat. 2016, 15, 186-195. [CrossRef]

49. Prabhu, R.S.; Patel, K.R.; Press, R.H.; Soltys, S.G.; Brown, P.D.; Mehta, M.P.; Asher, A.L.; Burri, S.H. Preoperative Vs Postoperative Radiosurgery For Resected Brain Metastases: A Review. Neurosurgery 2019, 84, 19-29. [CrossRef]

50. Atalar, B.; Choi, C.Y.; Harsh, G.R.t.; Chang, S.D.; Gibbs, I.C.; Adler, J.R.; Soltys, S.G. Cavity volume dynamics after resection of brain metastases and timing of postresection cavity stereotactic radiosurgery. Neurosurgery 2013, 72, 180-185. [CrossRef]

51. Jarvis, L.A.; Simmons, N.E.; Bellerive, M.; Erkmen, K.; Eskey, C.J.; Gladstone, D.J.; Hug, E.B.; Roberts, D.W.; Hartford, A.C. Tumor bed dynamics after surgical resection of brain metastases: Implications for postoperative radiosurgery. Int. J. Radiat. Oncol. Biol. Phys. 2012, 84, 943-948. [CrossRef] [PubMed]

52. Scharl, S.; Kirstein, A.; Kessel, K.A.; Duma, M.N.; Oechsner, M.; Straube, C.; Combs, S.E. Cavity volume changes after surgery of a brain metastasis-consequences for stereotactic radiation therapy. Strahlentherapie und Onkologie 2019, 195, 207-217. [CrossRef] [PubMed]

53. Ahmed, S.; Hamilton, J.; Colen, R.; Schellingerhout, D.; Vu, T.; Rao, G.; McAleer, M.F.; Mahajan, A. Change in postsurgical cavity size within the first 30 days correlates with extent of surrounding edema: Consequences for postoperative radiosurgery. J. Comput. Assist. Tomogr. 2014, 38, 457-460. [CrossRef] [PubMed]

54. El Shafie, R.A.; Tonndorf-Martini, E.; Schmitt, D.; Weber, D.; Celik, A.; Dresel, T.; Bernhardt, D.; Lang, K.; Hoegen, P.; Adeberg, S.; et al. Pre-Operative Versus Post-Operative Radiosurgery of Brain Metastases-Volumetric and Dosimetric Impact of Treatment Sequence and Margin Concept. Cancers 2019, 11, 294. [CrossRef]

55. Nedzi, L.A.; Kooy, H.; Alexander, E., 3rd; Gelman, R.S.; Loeffler, J.S. Variables associated with the development of complications from radiosurgery of intracranial tumors. Int. J. Radiat. Oncol. Biol. Phys. 1991, 21, 591-599. [CrossRef]

56. Shaw, E.; Scott, C.; Souhami, L.; Dinapoli, R.; Kline, R.; Loeffler, J.; Farnan, N. Single dose radiosurgical treatment of recurrent previously irradiated primary brain tumors and brain metastases: Final report of RTOG protocol 90-05. Int. J. Radiat. Oncol. Biol. Phys. 2000, 47, 291-298. [CrossRef]

57. Eitz, K.A.; Lo, S.S.; Soliman, H.; Sahgal, A.; Theriault, A.; Pinkham, M.B.; Foote, M.C.; Song, A.J.; Shi, W.; Redmond, K.J.; et al. Multi-institutional Analysis of Prognostic Factors and Outcomes After Hypofractionated Stereotactic Radiotherapy to the Resection Cavity in Patients With Brain Metastases. JAMA Oncol. 2020. [CrossRef]

58. Atalar, B.; Modlin, L.A.; Choi, C.Y.; Adler, J.R.; Gibbs, I.C.; Chang, S.D.; Harsh, G.R.T.; Li, G.; Nagpal, S.; Hanlon, A.; et al. Risk of leptomeningeal disease in patients treated with stereotactic radiosurgery targeting the postoperative resection cavity for brain metastases. Int. J. Radiat. Oncol. Biol. Phys. 2013, 87, 713-718. [CrossRef]

59. Ojerholm, E.; Lee, J.Y.; Thawani, J.P.; Miller, D.; O’Rourke, D.M.; Dorsey, J.F.; Geiger, G.A.; Nagda, S.; Kolker, J.D.; Lustig, R.A.; et al. Stereotactic radiosurgery to the resection bed for intracranial metastases and risk of leptomeningeal carcinomatosis. $J$. Neurosurg. 2014, 121, 75-83. [CrossRef]

60. Press, R.H.; Zhang, C.; Chowdhary, M.; Prabhu, R.S.; Ferris, M.J.; Xu, K.M.; Olson, J.J.; Eaton, B.R.; Shu, H.G.; Curran, W.J.; et al. Hemorrhagic and Cystic Brain Metastases Are Associated With an Increased Risk of Leptomeningeal Dissemination After Surgical Resection and Adjuvant Stereotactic Radiosurgery. Neurosurgery 2019, 85, 632-641. [CrossRef]

61. Suki, D.; Hatiboglu, M.A.; Patel, A.J.; Weinberg, J.S.; Groves, M.D.; Mahajan, A.; Sawaya, R. Comparative risk of leptomeningeal dissemination of cancer after surgery or stereotactic radiosurgery for a single supratentorial solid tumor metastasis. Neurosurgery 2009, 64, 664-674. [CrossRef] [PubMed]

62. Soliman, H.; Ruschin, M.; Angelov, L.; Brown, P.D.; Chiang, V.L.S.; Kirkpatrick, J.P.; Lo, S.S.; Mahajan, A.; Oh, K.S.; Sheehan, J.P.; et al. Consensus Contouring Guidelines for Postoperative Completely Resected Cavity Stereotactic Radiosurgery for Brain Metastases. Int. J. Radiat. Oncol. Biol. Phys. 2018, 100, 436-442. [CrossRef]

63. Patchell, R.A.; Tibbs, P.A.; Walsh, J.W.; Dempsey, R.J.; Maruyama, Y.; Kryscio, R.J.; Markesbery, W.R.; Macdonald, J.S.; Young, B. A randomized trial of surgery in the treatment of single metastases to the brain. N. Engl. J. Med. 1990, 322, 494-500. [CrossRef]

64. Molenaar, R.; Wiggenraad, R.; Verbeek-de Kanter, A.; Walchenbach, R.; Vecht, C. Relationship between volume, dose and local control in stereotactic radiosurgery of brain metastasis. Br. J. Neurosurg. 2009, 23, 170-178. [CrossRef] [PubMed]

65. Milano, M.T.; Grimm, J.; Niemierko, A.; Soltys, S.G.; Moiseenko, V.; Redmond, K.J.; Yorke, E.; Sahgal, A.; Xue, J.; Mahadevan, A.; et al. Single- and Multifraction Stereotactic Radiosurgery Dose/Volume Tolerances of the Brain. Int. J. Radiat. Oncol. Biol. Phys. 2020. [CrossRef]

66. Williams, B.J.; Suki, D.; Fox, B.D.; Pelloski, C.E.; Maldaun, M.V.; Sawaya, R.E.; Lang, F.F.; Rao, G. Stereotactic radiosurgery for metastatic brain tumors: A comprehensive review of complications. J. Neurosurg. 2009, 111, 439-448. [CrossRef] 
67. Brenner, D.J. The linear-quadratic model is an appropriate methodology for determining isoeffective doses at large doses per fraction. Semin. Radiat. Oncol. 2008, 18, 234-239. [CrossRef]

68. Combs, S.E.; Bilger, A.; Diehl, C.; Bretzinger, E.; Lorenz, H.; Oehlke, O.; Specht, H.M.; Kirstein, A.; Grosu, A.L. Multicenter analysis of stereotactic radiotherapy of the resection cavity in patients with brain metastases. Cancer Med. 2018, 7, $2319-2327$. [CrossRef] [PubMed]

69. Kumar, A.M.S.; Miller, J.; Hoffer, S.A.; Mansur, D.B.; Coffey, M.; Lo, S.S.; Sloan, A.E.; Machtay, M. Postoperative hypofractionated stereotactic brain radiation (HSRT) for resected brain metastases: Improved local control with higher BED(10). J. Neuro-Oncol. 2018, 139, 449-454. [CrossRef] [PubMed]

70. Soltys, S.G.; Adler, J.R.; Lipani, J.D.; Jackson, P.S.; Choi, C.Y.; Puataweepong, P.; White, S.; Gibbs, I.C.; Chang, S.D. Stereotactic radiosurgery of the postoperative resection cavity for brain metastases. Int. J. Radiat. Oncol. Biol. Phys. 2008, 70, 187-193. [CrossRef]

71. Specht, H.M.; Kessel, K.A.; Oechsner, M.; Meyer, B.; Zimmer, C.; Combs, S.E. HFSRT of the resection cavity in patients with brain metastases. Strahlentherapie und Onkologie 2016, 192, 368-376. [CrossRef] [PubMed]

72. Masucci, G.L. Hypofractionated Radiation Therapy for Large Brain Metastases. Front. Oncol. 2018, 8, 379. [CrossRef] [PubMed]

73. Schlienger, M.; Nataf, F.; Huguet, F.; Pene, F.; Foulquier, J.N.; Orthuon, A.; Roux, F.X.; Touboul, E. Hypofractionated stereotactic radiotherapy for brain metastases. Cancer Radiother. J. Soc. Fr. Radiother. Oncol. 2010, 14, 119-127. [CrossRef]

74. Minniti, G.; Paolini, S.; D’Andrea, G.; Lanzetta, G.; Cicone, F.; Confaloni, V.; Bozzao, A.; Esposito, V.; Osti, M. Outcomes of postoperative stereotactic radiosurgery to the resection cavity versus stereotactic radiosurgery alone for melanoma brain metastases. J. Neuro-Oncol. 2017, 132, 455-462. [CrossRef] [PubMed]

75. Akanda, Z.Z.; Hong, W.; Nahavandi, S.; Haghighi, N.; Phillips, C.; Kok, D.L. Post-operative stereotactic radiosurgery following excision of brain metastases: A systematic review and meta-analysis. Radiother. Oncol. J. Eur. Soc. Ther. Radiol. Oncol. 2020, 142, 27-35. [CrossRef] [PubMed]

76. Faruqi, S.; Ruschin, M.; Soliman, H.; Myrehaug, S.; Zeng, K.L.; Husain, Z.; Atenafu, E.; Tseng, C.L.; Das, S.; Perry, J.; et al. Adverse Radiation Effect After Hypofractionated Stereotactic Radiosurgery in 5 Daily Fractions for Surgical Cavities and Intact Brain Metastases. Int. J. Radiat. Oncol. Biol. Phys. 2020, 106, 772-779. [CrossRef]

77. Fahrig, A.; Ganslandt, O.; Lambrecht, U.; Grabenbauer, G.; Kleinert, G.; Sauer, R.; Hamm, K. Hypofractionated stereotactic radiotherapy for brain metastases-Results from three different dose concepts. Strahlentherapie und Onkologie 2007, 183, 625-630. [CrossRef]

78. Fokas, E.; Henzel, M.; Surber, G.; Kleinert, G.; Hamm, K.; Engenhart-Cabillic, R. Stereotactic radiosurgery and fractionated stereotactic radiotherapy: Comparison of efficacy and toxicity in 260 patients with brain metastases. J. Neuro-Oncol. 2012, 109, 91-98. [CrossRef]

79. Inoue, H.K.; Sato, H.; Suzuki, Y.; Saitoh, J.; Noda, S.E.; Seto, K.; Torikai, K.; Sakurai, H.; Nakano, T. Optimal hypofractionated conformal radiotherapy for large brain metastases in patients with high risk factors: A single-institutional prospective study. Radiat. Oncol. 2014, 9, 231. [CrossRef]

80. Marcrom, S.R.; McDonald, A.M.; Thompson, J.W.; Popple, R.A.; Riley, K.O.; Markert, J.M.; Willey, C.D.; Bredel, M.; Fiveash, J.B. Fractionated stereotactic radiation therapy for intact brain metastases. Adv. Radiat. Oncol. 2017, 2, 564-571. [CrossRef]

81. Keller, A.; Doré, M.; Cebula, H.; Thillays, F.; Proust, F.; Darié, I.; Martin, S.A.; Delpon, G.; Lefebvre, F.; Noël, G.; et al. Hypofractionated Stereotactic Radiation Therapy to the Resection Bed for Intracranial Metastases. Int. J. Radiat. Oncol. Biol. Phys. 2017, 99, 1179-1189. [CrossRef] [PubMed]

82. Timmerman, R.D. An overview of hypofractionation and introduction to this issue of seminars in radiation oncology. Semin. Radiat. Oncol. 2008, 18, 215-222. [CrossRef] [PubMed]

83. Graber, J.J.; Cobbs, C.S.; Olson, J.J. Congress of Neurological Surgeons Systematic Review and Evidence-Based Guidelines on the Use of Stereotactic Radiosurgery in the Treatment of Adults With Metastatic Brain Tumors. Neurosurgery 2019, 84, E168-E170. [CrossRef] [PubMed] 